\title{
EMERGENCY COMMUNICATIONS NETWORK FOR DISASTERS MANAGEMENT IN VENEZUELA
}

\author{
C. Burguillos ${ }^{1} *$, H. Deng ${ }^{2}$ \\ ${ }^{1}$ Regional Centre for Space Science and Technology Education in Asia and the Pacific, International School Beihang University, \\ No. 37 Xueyuan Road, 100191, Beijing, China - shincomlabvene@ hotmail.com \\ ${ }^{2}$ School of Electronic and Information Engineering, Beihang University, No. 37 Xueyuan Road, 100191, Beijing, China - \\ denghui19@sina.com
}

\section{Commission III, WG III/1}

KEY WORDS: Space Technology Applications, Disasters Management, Emergency Communications Network, VENESAT-1, VRSS-1, VRSS-2, Technologies Solutions, Images Exchange

\begin{abstract}
:
The integration and use of different space technology applications for disasters management, play an important role at the time of prevents the causes and mitigates the effects of the natural disasters. Nevertheless, the space technology counts with the appropriate technological resources to provide the accurate and timely information required to support in the decision making in case of disasters. Considering the aforementioned aspects, in this research is presented the design and implementation of an Emergency Communications Network for Disasters Management in Venezuela. Network based on the design of a topology that integrates the satellites platforms in orbit operation under administration of Venezuelan state, such as: the communications satellite VENESAT-1 and the remote sensing satellites VRSS-1 and VRSS-2; as well as their ground stations with the aim to implement an emergency communications network to be activated in case of disasters which affect the public and private communications infrastructures in Venezuela. In this regard, to design the network several technical and operational specifications were formulated, between them: Emergency Strategies to Maneuver the VRSS-1 and VRSS-2 satellites for optimal images capture and processing, characterization of the VENESAT-1 transponders and radiofrequencies for emergency communications services, technologies solutions formulation and communications links design for disaster management. As result, the emergency network designed allows to put in practice diverse communications technologies solutions and different scheme or media for images exchange between the areas affected for disasters and the entities involved in the disasters management tasks, providing useful data for emergency response and infrastructures recovery.
\end{abstract}

\section{INTRODUCCTION}

Nowadays on a global scale, the integration and implementation of different space technology applications that help to design alternative communications networks to mitigate the disasters impact on the terrestrial communications infrastructures, have a significant demand in the Disasters Management field. Since, during the various stages of a disaster, the flow of information between disaster management actors and the population in general is a crucial and necessary element to provide an expeditious and timely response to the issues surrounding the disaster. But in most cases, the terrestrial communications infrastructures as cellular telephone networks, fiber optic networks, microwave networks, fixed telephony services, TV and commercial radio services, included the internet services, can be affected by the impacts of the natural disaster that has occurred, causing this phenomenon the unavailability of the communications services; fact that has a significant impact in all the processes inherent to the preparedness, response and recovery in disasters situations. On the other hand, the remote sensing satellites is a tool that facilitates in proper way understanding the nature of the damage caused by the disaster and in turn, makes available the necessary information to assists in the distinct phases involved in the disaster management.
From this point of view, the integration of the remote sensing satellites and the communications Satellites inside an emergency network to carry out the disasters management, represent a valuable and helpful source to increase the capacities of monitoring, manage and flow of all the critical data related to a disaster in specific. Capacities that improve the emergency response time and also establish the required measures to reduce the disaster impacts. In consequences, for the past years, extensive works have been done that proposing the integration of the space technology applications for disaster management. More specifically, (Mehdi, A., 2012b), studied the role of the mobile satellite services and remote sensing satellites in disaster management, with the aim to decrease the human casualties in natural events through the utilization of both technologies. (ESCAP, 2013a), explored different space technology applications and their role in the disasters mitigation. Space technologies, such as: earth observation satellites, communication satellites, meteorological satellites and global navigation satellites systems (GNSS), establishing the highly importance of thereof in the risk reduction and disaster management.

However, in this paper is presented the design and implementation of an Emergency Communications Network for Disasters Management in Venezuela, based on the design of a

\footnotetext{
* Corresponding author
} 
topology that integrates the satellites platforms in orbit operation under administration of the Bolivarian Agency for Space Activities (ABAE), such as: the communications satellite VENESAT-1 and the remote sensing satellites VRSS-1 and VRSS-2; as well as their ground stations in a emergency network that allows put into operation a novel infrastructure in Venezuela for disasters management with the capacities of provide diverse communications technologies solutions and different schemes or media for images exchange between the areas affected for the occurrence of disasters and the entities involved in the disasters management tasks, providing useful data for emergency response and infrastructures recovery in the event of disasters of any type or magnitude which affect the public and private communications infrastructures.

\subsection{Venezuela Disasters Occurrence}

The hydrography of Venezuela is very wide being able to find a variety of rivers, lakes and six main hydrography basins. (Ministry of Mines and Hydrocarbons, 1970b). Likewise, are located in different parts of the Venezuela territory sixteen (16) Main geological faults systems, these are: Oca-Anco, Urumaco, Rio Seco, Valera, Tuname, Bocono, la Victoria, Rio Guarico, Tacagua el Avila, Tacat, Piritu, el Pilar, San Mateo, Los Bajos, San Sebastian and the Flexion Frontal Sur Andiana. The Bocono faults, San Sebastian faults, the Pilar y Oca-Ancon faults are the areas of greatest seismic activity in the country. (Rondon, J., 2015b). According with the (World risk Report, 2016) Index calculated by the United Nations University for Environment and Human Security, Venezuela is located in the position 76 between 173 countries evaluated. This report systematically considers a country's vulnerability, and its exposure to natural hazards to determine the ranking of countries around the world based on their disaster risk, taking in consideration the risk of becoming a victim of a disaster as a result of vulnerability and natural hazards, such as: earthquakes, storms, floods, droughts and sea level. The Figure 1 shows the major disasters occurred in Venezuela with their respectively landmark.

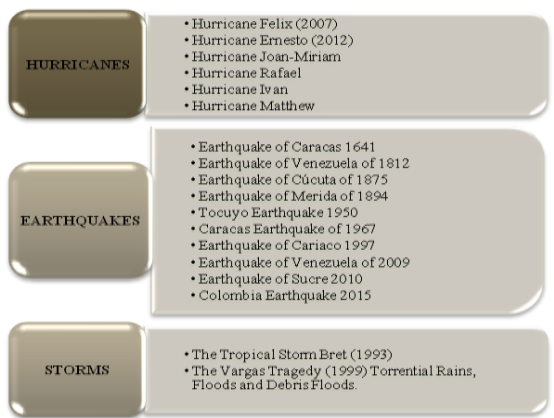

Figure 1. Major disasters occurred in Venezuela

In particular, the Vargas tragedy has been one of the most important disasters in the last twenty years in Venezuela. This disaster struck the Vargas State of Venezuela on December 15, 1999, when the torrential rains and the flash floods and big varieties of debris flowed from different parts. This tragedy killed tens of thousands of people, destroyed thousands of homes, and led to the complete collapse of the state's infrastructure. According to relief workers, the neighbourhood of the Corales was buried under 3 meters $(9.8 \mathrm{ft})$ of mud and a high percentage of homes were simply swept away to the ocean. Whole towns like Cerro Grande and Carmen of Uria completely disappeared. As much as $10 \%$ of the population of Vargas perished during this event. It should be pointed out, in reference to all the aforementioned events, that Venezuela is a country susceptible to the occurrence of different natural phenomena, which demands the implementation of tools or technology infrastructures adequate to carry out the disasters management. Thus, the Emergency Communications Network proposed in this research becomes in an important resource to mitigate the damages in the Venezuelan communications infrastructures, due to the effects caused for the disasters that could happen.

\subsection{The Main Role of the Emergency Communications Network in the Disasters Management}

(ITU, 2003a), proposes that: "when a disaster strikes, telecommunications save lives". Therefore, the Information and Communication Technology (ICT) has been recognized as a powerful tool for the national economic, social and culture development which aim to raise productivity and improve the quality of life. In this regard, many specialists in disaster management have collected in the time, different field experiences in reference to the importance of maintaining the operability of the communications services, as the primary challenge presented during and after the disaster. For such reason, the communications services are one of the major pillars for the disaster management. During the disaster the demand of: fast data access, systems integration and interoperability, timeliness and updating of the information, standardization of information and easy access to the communications services are the essentials functions that must be guaranteed for a communications network in all stage of the disaster. In figure 2, is described in a graphic way how the communications systems fail when they are affected by different disasters. Additionally, the same figure point out each disaster's phase in which are considered the use of the communications systems and also specified the general plan of action to follow with the objective to prepare in advance the communications services and their infrastructures to mitigate the effects produced by the disasters.

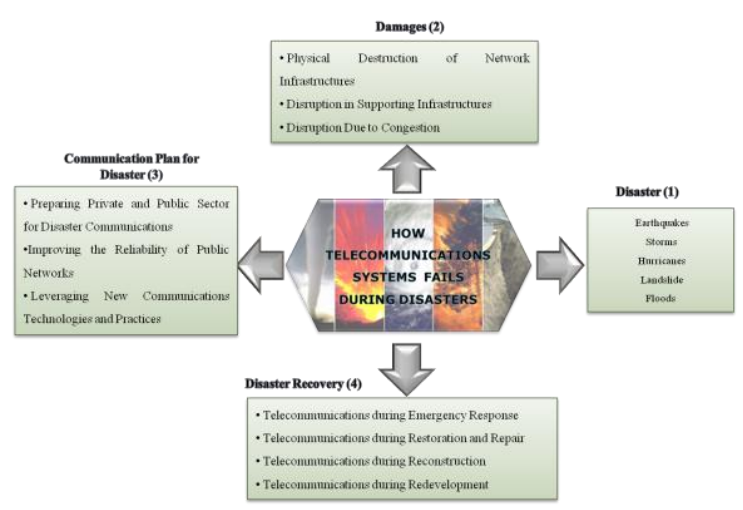

Figure 2. How the communications systems fail in disaster

Since, the terrestrial communication systems are often entirely or partially damaged during the disasters is very important count with alternative media to support the conventional communications systems in case of disasters, for the reason that the demand of information and communications services explosively increases once the disaster arose. In this respect, for the past decade the use of the communications satellite systems in disaster has increased since this technology is the only option quick a reliable after terrestrial communication infrastructures are affected for the disasters impacts to support or replace the terrestrial networks. Moreover, the satellite terminals can easily be set up in disaster zones to provide good coverage and facilitate the activation of the required or crucial services in the 
areas affected for disasters. In conclusion, the use of the communications satellite resources during the disasters, improve the timely flow of crucial information needed for appropriate assistance to be delivered before, during and after the disaster.

\section{EMERGENCY COMMUNICATIONS NETWORK DESIGN}

\subsection{Proposed Methodology}

The design and implementation of the Emergency Communications Network for Disasters Management in Venezuela, integrated by the communications satellite VENESAT-1, the remote sensing satellites VRSS-1 and VRSS2 and also their ground stations, can be divided systematically into the following main tasks: In first place, is formulated an emergency strategy to maneuver the remote sensing satellites VRSS- 1 and VRSS-2 in orbit for Optimal Images Capture in case of Disasters, considering the spatial and spectral resolution of both platform, then is designed a model to images management and processing for the VRSS-1 and VRSS-2 satellites at ground segment level in emergency, following is carried out the technical characterization of the VENESAT-1 transponders and radiofrequency spectrum available in C-Band, $\mathrm{Ku}-\mathrm{B}$ and and Ka-band for emergency communications services implementation, afterward different technologies solutions are formulated for disaster management base on solutions adequate to transmit and receive distinct types of data and images, also are designed the communications link budget for priority services in emergency and finally is designed the topology with the infrastructure required to integrate the satellites VENESAT1, VRSS-1 and VRSS-2 to operate in the emergency communications network.

\subsection{VRSS-1 and VRSS-2 Operational Strategy to} Management the Spatial Resolution in Disasters

The term resolution in remote sensing satellites is used to characterize the resolving power captured by the sensor, which includes not only the ability to identify the presence of two objects, but also their properties. It is usually refers to the size of the instantaneous field of view (IFOV) of the sensor. The resolution is based on criteria such as: geometrical properties of the sensor system, ability to distinguish between points, ability to measure the periodicity of repetitive targets and ability to measure the spectral properties of small targets. It is important highlight, that in disasters management the remote sensing spatial resolution is a key characteristic that must be took in consideration, since depend on the type of the disaster occurred, different spatial resolutions used to images acquisitions will provide the required detail of the images and specifics characteristics of the area observed or affected for one or more disasters. In consequence, for disaster management and emergency response the remote sensing spatial resolution is used mainly to recognize the infrastructure affected or damages existing on the surface scanned, to establish the necessary scale to carry out the images analysis, to define the location precision and characterizes the areal accuracy. On the other hand, when is analyzed the remote sensing spatial resolution must be also taking in count the satellite spatial coverage because this specifies the geographical coverage of the satellite in a interval of time, and it is also intrinsically related to the spatial resolution, since the satellite coverage variations due to the land scanning angles changes, also produce variations in the spatial resolution.

The figure 3, describes the satellite coverage on land and it is notice on it the maximum sweep angle (FOV) that represents the total area observed by the satellite according to its radiometric characteristics. Also, the figure shows the instantaneous field of view (IFOV) which is the minimum solid angle subtended by the sensor opening from a given altitude at one particular moment in time. The size of the area viewed is determined by multiplying the IFOV by the distance from the ground to the sensor. This area on the ground is called the resolution cell and determines the sensor maximum spatial resolution and finally the satellite trace or trajectory. It should be borne in mind that the size of the pixel is modified throughout the sweep of the sensor due to the curvature of the earth. Depending on the applications, different spatial resolution may be required. For example, there may be large differences on the land surface in small areas, so it is necessary to observe them with a satellite system that has high resolution, whereas at sea the changes occur on a large scale and therefore it is necessary to have a greater coverage. The same applies to meteorological observations, where cloud fronts must be covered in an extended form, where a low resolution is necessary.

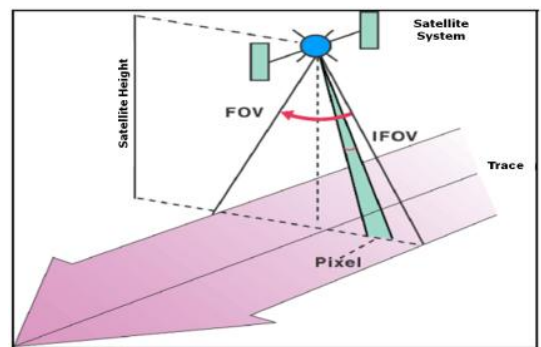

Figure 3. Remote sensing satellite land coverage

According to the aforementioned, for VRSS-1 and VRSS-2 satellites technical aspects, such as: Satellite Swath Coverage Area, Potential Satellite Swath Coverage Area in Nadir and Off Nadir Angle, Computing Pixel Size in Nadir and Off Nadir Angle and Dwell Time for an Along Track Scan, are proposed to be managed through the operational strategies with the purpose to obtain an adequate Spatial Resolution, Spatial Coverage and a good performance of both satellites during the disaster management.

A general overview of the PAN and Multispectral Camera (PMC) and Wide Swath Multispectral Camera (WMC) Camera of the VRSS-1 satellite are shown in Table 1. Also in Table 1 the general characteristics of the High Resolution Camera (HRC) and Infrared Camera (IRC) of the VRSS-2 satellite are described. (ABAE, 2010. ABAE, 2016).

\begin{tabular}{|c|c|c|c|}
\hline Satellite & Camera & Resolution & FOV (Nadir) \\
\hline VRSS-1 & PMC & $\begin{array}{c}\text { PAN: } \leq 2.5 \mathrm{~m} \\
\text { MS: } \leq 10 \mathrm{~m}\end{array}$ & $5.15^{\circ}$ \\
\hline VRSS-1 & WMC & $\leq 16 \mathrm{~m}$ & $16.44^{\circ}$ \\
\hline VRSS-2 & HRC & $\begin{array}{c}\text { Pam } \leq 1 \mathrm{~m} \\
\text { MS } \leq 4 \mathrm{~m}\end{array}$ & $2.93^{\circ}$ \\
\hline VRSS-2 & IRC & $\begin{array}{c}30 \mathrm{~m} \text { (SWIR) } \\
60 \mathrm{~m} \text { (LWIR) }\end{array}$ & $2.8^{\circ}$ \\
\hline
\end{tabular}

Table 1. VRSS-1and VRSS-2 Cameras Overview 


\subsubsection{VRSS-1 and VRSS-2 land swath coverage estimation $\left(\mathrm{LSC}_{\mathrm{S}}\right)$}

The VRSS-1 and VRSS-2 viewing angle of the sensors can be adjusted to look to different side of the satellite's vertical (nadir) track. The VRSS-1 has the ability to point their sensors up to $31^{\circ}$ and the VRSS-2 up to $29^{\circ}$, from nadir through roll manoeuvre, which allows increasing their scan angles and swath coverage. the changes in the pointing angles of these satellites provide the capacity to observe a major extension of land but must be took in count that the ground area observe can be distorted at the extremes of the observation due to the curvature of the earth and others factors. Particularly, in case of disasters management different satellite pointing angle are useful to record a same area affected for a disasters from two different angles, also assists to carry out the images analysis in a three dimensional model, in the same way helps to implement the mapping and interpretation of the areas affected for disasters with the objective to formulate simulations of damages that facilitate the emergency response tasks.

In this sense, the proposed operational methodology to management the Land Swath Coverage Estimation ( $\mathrm{LSC}_{\mathrm{S}}$ ) for VRSS-1 and VRSS-2 in emergency response is in first place base on the determination of the minimum (in Nadir) and maximum (Off Nadir) Land Swath Coverage, calculated taking as reference the Field of View (FOV) specifications of the cameras installed in each satellites platform and in second place, in the estimation of the Potential Land Swath Coverage $\left(\mathrm{LSC}_{\mathrm{P}}\right)$ for VRSS-1 and VRSS-2, through the spherical trigonometry mathematical method considering the law of sines for this aim. The equation (1) specified below is proposed to estimate the VRSS-1 and VRSS-2 Land Swath Coverage minimum (in Nadir) and maximum (Off Nadir).

$$
\mathrm{LSC}_{\mathrm{s}}=2 \cdot \mathrm{R}_{\mathrm{s}} \cdot\left(\tan \mathrm{FOV}_{\mathrm{s}}\right)
$$

Where $\quad \mathrm{LSC}_{\mathrm{s}}=$ Satellite Land Swath Coverage Estimation

$$
\mathrm{R}_{\mathrm{s}}=\text { Satellite Ranging (High) }
$$

$\tan =$ Tangent

$\mathrm{FOV}_{\mathrm{s}}=$ Sensor Field of View

As example using the equation (1) is carry out the computation to estimate the Land Swath Coverage for the PAN and Multispectral Camera (PMC) of the VRSS-1 and also to the High Resolution Camera (HRC) of VRSS-2; taking into consideration, a nominal operation altitude for both satellite of: $640 \mathrm{~km}$. The results are specified in Table 2.

\begin{tabular}{|c|c|c|c|c|c|}
\hline Satellite & Camera & $\begin{array}{c}\text { FOV } \\
\text { (Nadir) }\end{array}$ & $\begin{array}{c}\text { FOV } \\
\text { (Max } \\
\text { Off } \\
\text { Nadir) }\end{array}$ & $\begin{array}{c}\text { LSC } \\
\text { (Nadir) }\end{array}$ & $\begin{array}{c}\text { LSC } \\
\text { (Max } \\
\text { Off } \\
\text { Nadir) }\end{array}$ \\
\hline VRSS-1 & PMC & $5.15^{\circ}$ & $31^{\circ}$ & $\begin{array}{c}115.328 \\
\mathrm{~km}\end{array}$ & $\begin{array}{c}768 \\
\mathrm{~km}\end{array}$ \\
\hline VRSS-2 & HRC & $2.93^{\circ}$ & $29^{\circ}$ & $\begin{array}{c}65.51 \\
\mathrm{~km}\end{array}$ & $\begin{array}{c}709 \\
\mathrm{~km}\end{array}$ \\
\hline
\end{tabular}

Table 2. VRSS-1 and VRSS-2 Satellites Land Swath Coverage Estimation

In Table 2, the results put in evidence that the VRSS-1 and VRSS-2 have a wide Land Swath Coverage, when is changed their land scan angles through the tilt capacity. Ability useful in disasters since allows providing a quick response to cover specific areas affected for disasters in the less time possible in function to the lateral view in degrees from the vertical to any direction which is available through the roll maneuver for both platforms.

\subsubsection{VRSS-1 and VRSS-2 Potential Land Swath Coverage in Nadir and Off Nadir Angle $\left(\mathrm{LSC}_{\mathrm{P}}\right)$}

The estimation of the potential remote sensing satellite Land Swath Coverage ( LSC $_{\mathrm{P}}$ ) scanned on the surface in Nadir and Off Nadir Angle in case of disaster or emergency response is a practical strategy to identify the possible swath width area to be scanned for the satellite in the futures passes. In consequence, this strategy puts up the facility to plan the potential areas required to be scanned in specific time by the satellite in the expected passes. Strategy essential for the disasters management, since assists to predict in advance the extension of the area that can be scanned for the satellite affected by the occurrence of disasters. There are three mathematical approaches used to computing the satellite Potential Land Swath Coverage, these are: planar surface assumption, spherical assumption using intersecting lines and spherical assumption using an oblique triangle. (Hodgson, M. et al., 2008a). Essentially, the spherical assumption using the oblique triangle solution earth model (figure 4) is the most used method to predict the Potential Land Swath Coverage.

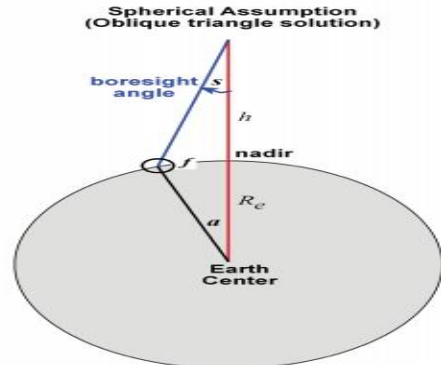

Figure 4. Spherical assumption geometry using the Oblique Triangle

The spherical assumption method consists in a mathematical solution through which is projected a line from the satellite until the plane perpendicular to the Earth's surface. At this intersection point is created an angle denominated no include angle (f) (Figure 4); that is the IFOV of the sensor, referenced to an oblique triangle and subsequently three more known angles, defined as included angles (Figure 4), they are formed for the satellite altitude $(\mathrm{h})$, earth radius $\left(\mathrm{R}_{\mathrm{e}}\right)$, and the boresight angle or FOV (s). The IFOV is the area on the ground that is viewed by the sensor at a given instant of time. As such, it usually represents the ground area that is represented by each pixel in a remotely sensed image. The IFOV can be indicated as the ground dimensions of each pixel, or as the instantaneous angular measurement of the sensor field of view (Mather, 1987). In this regard, putting in practice the aforementioned mathematical approach through the law of the sines is possible calculate the potential satellite land swath coverage on the surface. Therefore, the mathematical formulation to determine the VRSS-1 and VRSS-2 potential Land Swath Coverage using the law of the sines is the next:

Since, the three angles $(\alpha, \emptyset, s)$ specified in the figure 4 must sum 180 degrees, so $f=180-\alpha$ - s, solving $(\alpha)$ through the law of the sines, we have:

$$
\alpha=\sin ^{-1} \cdot\left(\frac{\sin (s) \cdot\left(R_{e}+h\right)}{R_{e}}\right)-s
$$


Where

$$
\begin{aligned}
& \alpha=\text { No include angle or IFOV } \\
& s=\text { Boresight angle or FOV } \\
& R_{e}=\text { Radius of the Earth } \\
& h=\text { Satellite height or range }
\end{aligned}
$$

However, to computing the Satellite Potential Land Swath Coverage is used the equation (3).

$$
L S W_{p}=\left(\frac{\alpha}{2 \pi}\right) \cdot R_{e}
$$

Where $\quad \mathrm{LSC}_{\mathrm{p}}=$ Satellite Potential Land Swath Coverage $\alpha=$ No include Angle or IFOV

$\mathrm{R}_{\mathrm{e}}=$ Radius of the Earth

For instance, through the above formulation assuming $\mathrm{s}=20^{\circ}$ for the High Resolution Camera (HRC) of the VRSS-2 after roll maneuver, a satellite height or range nominal $=640 \mathrm{~km}$ and Radius of the Earth $=6378.137 \mathrm{~km}$, first solving $(\alpha)$ with the equation (2) is calculated the satellite sensor IFOV $=2.10^{\circ}$, then with the equation (3) is computed for the VRSS-2 a Potential Land Swath Coverage $=2132.81 \mathrm{~km}$. These mean that the VRSS-2 with the HRC in consecutive passes in different adjacent orbits can cover $2132.81 \mathrm{~km}$ of land over the Venezuela territory. Therefore, since the maximum swath coverage of the HRC off Nadir to $29^{\circ}$ of inclination (maximum Off Nadir angle) is $=709 \mathrm{~km}$ (according with Table 3 ) and the Potential Land Swath Coverage $=2132.81 \mathrm{~km}$ computed from the equation (3), we can assume roughly that the period to cover the Potential Land Swath Coverage calculated is: 2132810/ $709000=3$ days. Figure 5 shows the VRSS- 2 cameras access capacity with $\pm 29^{\circ}$ roll maneuver.

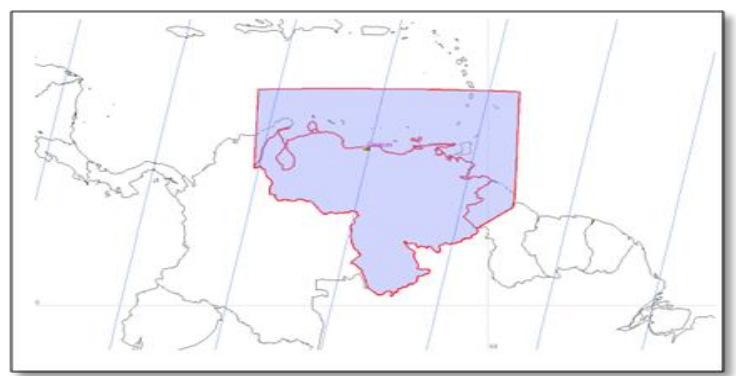

Figure 5. VRSS-2 Camera access capacity with $\pm 29^{\circ}$ roll maneuver in 4 days

In resume, the VRSS-1and VRSS-2 Potential Land Swath Coverage prediction is useful to planning the images collection opportunities of the areas required to be scanned immediately after a disaster event for both satellites. More accurate Potential Land Swath Coverage results for VRSS-1 and VRSS-2 in real operation is possible using the satellite range obtained from periodic ephemerides prediction provided for the operational softwares installed in the ground control stations of the VRSS-1 and VRSS-2. In view of the fact that the satellite fly height influences its FOV, through the which is also affected its swath width coverage; additionally beside the strategy to maneuver the VRSS-1 and VRSS-2 in order to get different FOV with the aim to cover and revisit distinct areas that can be affected for disasters, technical aspects already mentioned before about the spatial resolution, such as: computing pixels size in nadir and off nadir angle and dwell time for an along track scan are also considering and calculated inside the strategy proposed with the objective to get a better coverage and images of the required areas in the course of the emergency response in case of disasters.

\subsubsection{Computing Pixels Size in Nadir and Off Nadir Angle}

A pixel size is the smallest size that satellite images cover. The Satellite images are organized in rows and columns called raster imagery and each pixel has a certain spatial size. The pixels resolution varies with the sensor scan angle. These angles changes make that the pixel dimensions become increasingly distorted away from nadir as view zenith angles increase. In consequence, at the extreme edges of the scan the resolution is distorted along track direction and also across track direction. (Canada center for Remote Sensing, 2006b). Important aspects that have to be analyzed at the moment of maneuver the scan angle of the VRSS-1 and VRSS-2 to increase the land swath coverage of both platforms, with the purpose to cover a specific extension of land, which leads also to ensuring the capture of images with low distortion in diverse emergency operations. In Figure 6 is presented the spatial pixels size geometric representation in Nadir and off Nadir angle.

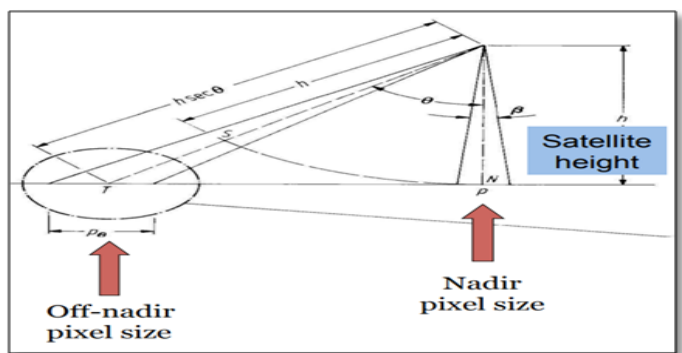

Figure 6. Spatial pixels size geometric representation in Nadir and off Nadir angle

Specifically, in relation to the spatial area represented by each pixel according to the sensor resolution, the VRSS-1 has two (02) PAN and Multispectral Camera (PMC) with optical PAN and MS detectors integrated in each cameras to cover both functions simultaneously; for the PAN sensor the ground sampling distance (GSD) in Nadir is $\leq 2.5 \mathrm{~m}$ with a pixel size $\leq 6.25 \mathrm{~m}^{2}$,in MS function has a GSD in Nadir of $\leq 10 \mathrm{~m}$ with pixel size $\leq 100 \mathrm{~m}^{2}$ two (02) Wide Swath Multispectral Camera (WMC) with four (04) spectral bands and GSD in Nadir $\leq 16 \mathrm{~m}^{2}$ and pixel size $\leq 256 \mathrm{~m}^{2}$.The VRSS-2 has one (01) High Resolution Camera (HRC) which also has multiple function optical detector to produce PAN and MS data at the same time. For PAN function the ground sampling distance in Nadir is $\leq 1 \mathrm{~m}$ this mean that the pixel size is $\leq 1 \mathrm{~m}^{2}$ or MS function in Nadir is $\leq 4 \mathrm{~m}$ with pixel size $\leq 16 \mathrm{~m}^{2}$, the shortwave infrared (SWIR) in Nadir has a resolution $\leq 30 \mathrm{~m}$, its pixel size is $\leq 900$ $\mathrm{m}^{2}$ and the Long Wave Infra-Red (LWIR) $\leq 60 \mathrm{~m}$ in Nadir with a pixel size $\leq 3600 \mathrm{~m}^{2}$ The mathematical solution to compute the Spatial Pixels Size in Nadir and off Nadir Angle is specified as follow:

$$
S P_{S}=2 \cdot h \cdot \operatorname{tag}\left(\frac{\beta}{2}\right)
$$

Where $\quad \mathrm{SP}_{\mathrm{s}}=$ Spatial pixels size

$\mathrm{h}=$ Satellite Height or Range

$\tan =$ Tangent

$\beta=$ Sensor field of view in Nadir

Therefore, using the previously formulation and taking into consideration for the next example, one (01) Wide Swath Multispectral Camera (WMC), of the VRSS-1 with $\mathrm{FOV}=16.44^{\circ}$ in Nadir and maximum $\mathrm{FOV}=31^{\circ}$ off Nadir thought roll maneuver, considering a nominal satellite height or 
range of: $645 \mathrm{Km}$, from the equation (4), is computed the spatial pixels size for this camera in Nadir, which is $\leq 184.83$ $\mathrm{Km}$, since this CCD camera has 12,000 pixels with $6.5 \mu \mathrm{m}$ of size, it can be assumed that the camera effective resolution is: $\mathrm{CE}_{\mathrm{r}}=184830 / 12000=15.40 \mathrm{~m}$ in Nadir equivalent to $225 \mathrm{~m}^{2}$ spatial pixel size. In the same way, with the equation (4) is carry out the calculation of the pixels size at maximum off Nadir angle allows for this camera. However, the spatial pixels size for this camera at maximum off Nadir is $\leq 354.975 \mathrm{Km}$, as already know this camera has 12,000 pixels, so the camera effective resolution, $\mathrm{CE}_{\mathrm{r}}=354975 / 12000=29.58 \mathrm{~m}$ off Nadir equivalent to $875 \mathrm{~m}^{2}$ spatial pixel size. In brief, with this result is easy to notice that the ground area represented by pixels at the nadir will have major resolution than those pixels which are off-nadir. This means that spatial resolution will vary from the image centre to the swath edge. Important issues to be considering in the moment to change the satellite scan angle in case of disasters.

\subsubsection{Dwell Time for an Along Track Scan}

The VRSS-1 and VRSS-2 have cameras of the type Push broom and use a linear array of detectors to cover all the pixels in the across-track dimension at the same time (Figure 7). This allows a much longer detector dwell time than the cross-track scanner on each surface pixel, thus allowing much higher sensitivity and a narrower bandwidth of observation. In this sense, the dwell time is the amount of time a scanner has to collect photons from a ground resolution cell.

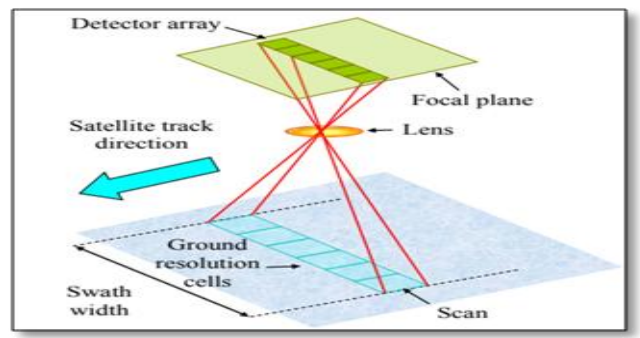

Figure 7. Push Broom camera a Long Track Scan

Nevertheless, the Dwell time depends on some factors, such as: satellite speed, width of scan line, time per scan line and time per pixel. Period of time that required be estimated in case of maneuver the VRSS-1 and VRSS- 2 to scan areas affected for disasters through different scan angles.

The mathematical approach applicable to calculate the Dwell time considering the VRSS-1 and VRSS-2 spatial resolution is:

$$
D T_{a t s}=\left(\frac{D T P_{s}}{S a t_{v}}\right)
$$

Where $\quad \mathrm{DT}_{\text {ats }}=$ Dwell time for an along track scan

DTP $_{\mathrm{s}}=$ Down track pixel size

$\mathrm{Sat}_{\mathrm{v}}=$ Satellite orbital velocity

\subsection{VRSS-1 and VRSS-2 Operational Strategy to Management the Spectral Resolution in Disasters}

The remote sensing satellite spectral resolution is represented by the spectral band width of the filter and the sensitiveness of its detector. Likewise, the spectral resolution defines the ability that have a sensor to resolve the energy received in specific spectral bandwidth to characterize different constituents of earth surface. The finer the spectral resolution, the narrower the wavelength ranges for a particular channel or band. In this respect, the VRSS-1 has the following spectral resolution for the PMC: in PAN: $0.45-0.90 \mu \mathrm{m}$; in MS band: B1/blue: $0.45-$ $0.52 \mu \mathrm{m}, \mathrm{B} 2 /$ green: $0.52-0.59 \mu \mathrm{m}, \mathrm{B} 3 /$ red: $0.63-0.69 \mu \mathrm{m}$ and B4/NIR: $0.77-0.89 \mu \mathrm{m}$. for the WMC: B1/blue: $0.45-0.52 \mu \mathrm{m}$, B2/green: $0.52-0.59 \mu \mathrm{m}, \mathrm{B} 3 / \mathrm{red}: 0.63-0.69 \mu \mathrm{m}$ and in B4/NIR: $0.77-0.89 \mu \mathrm{m}$. the VRSS-2 spectral resolution for the HRC is: in PAN band: $0.50-0.80 \mu \mathrm{m}$; in MS band: B1/blue: $0.45-0.52 \mu \mathrm{m}$, B2/green: $0.52-0.59 \mu \mathrm{m}, \mathrm{B} 3 / \mathrm{red}$ : $0.63-0.69 \mu \mathrm{m}$, and in B4/NIR: $0.77-0.89 \mu \mathrm{m}$. For the IRC the spectral resolution is: in SWIR: $0.9 \pm 0.05 \mu \mathrm{m} \sim 1.1 \pm 0.05 \mu \mathrm{m}, 1.18 \pm 0.05 \mu \mathrm{m} \sim 1.3 \pm 0.05 \mu \mathrm{m}$, $1.55 \pm 0.05 \mu \mathrm{m} \sim 1.7 \pm 0.05 \mu \mathrm{m}$ and in LWIR is: $10.3 \pm 0.1 \mu \mathrm{m} \sim$ $11.3 \pm 0.1 \mu \mathrm{m}$ and $11.5 \pm 0.1 \mu \mathrm{m} \sim 12.5 \pm 0.1 \mu \mathrm{m}$. Each sensor of the VRSS-1 and VRSS-2 is designed with a specific purpose focusing on their spectral bands defined to collect different types of images, taking advantage of the microwave spectrum and its incidence angle, through which are defined the applications best suited for each sensor. General speaking, each object and surface characteristics have their own spectra signature due to the responses over distinct electromagnetic wavelength ranges, this allows establishing the difference between classes of features and details in the images.

From this perspective, regarding the VRSS-1 and VRSS-2 spectral resolution, important methods are proposed to be implemented in case of disasters with the object to management the spectral resolution capacity, such as: data base implementation with the spectral derivation of the signature (tagging) for every pixel within the satellites field of view, implementation of the wavelength-specific criteria for spectral features, media helpful to achieve real-time analysis of the spectral data, discrimination and analysis of the scene colours that potentially can be presented in diverse images, base on a library of known spectral signatures or targets previously study. In Table 4 is provided an overview of the VRSS- 1 and VRSS-2 spectral resolution potential applications useful for disaster management.

\begin{tabular}{|c|l|}
\hline Band & \multicolumn{1}{|c|}{$\begin{array}{c}\text { VRSS-1 and VRSS-2 Potential Spectral } \\
\text { Uses in Case of Disasters }\end{array}$} \\
\hline MS Band & $\begin{array}{l}\text { Oil spill boundaries, specific materials and } \\
\text { components of aerosols, gas plumes, and other } \\
\text { effluents, Bathymetry and Hydrology } \\
\text { products, identification and mapping wildfire } \\
\text { threats, including hazardous fuel } \\
\text { accumulations, determine vegetation classes, } \\
\text { soil types, and hydrology. Since the signatures } \\
\text { are unique for each material, allows for } \\
\text { discrimination of one include material to } \\
\text { another based on spectral signatures of the } \\
\text { materials. Limitations: Weather Dependent }\end{array}$ \\
\hline IR Band & $\begin{array}{l}\text { Surface temperatures determination, } \\
\text { monitoring of eruptions and precursor events, } \\
\text { gas emissions, eruption plumes, development } \\
\text { of lava lakes, eruptive history and eruptive } \\
\text { potential, extent and effects of wildfires, } \\
\text { flooding, coastal erosion, earthquake damage, } \\
\text { and tsunami damage, mapping of surface soils, } \\
\text { monitoring desertification and deforestation. }\end{array}$ \\
\hline
\end{tabular}

Table 3. VRSS-1 and VRSS-2 Potential spectral uses in case of disasters

\subsection{VRSS-1 and VRSS-2 Operational Strategy to Images Management in Disasters}

In major of the cases during the disasters occurrence, different organizations, at national, state and district level involved in 
the tasks related to the disasters management demand a huge quantity of images that provide them the information necessary to evaluate the damages post disasters, to identify possible vulnerability or carry out hazard assessment in the disaster relief phase. Likewise, the images are required with diverse characteristics according to the phenomenon produced or in relation with some details in specific of the area affected. In this sense, the availability of different images levels of spatial data and spectral data is useful information in the various stages of disaster management. In this respect, the VRSS-1 and VRSS-2 system integrated with their ground segment has the capability to provide a variety of images levels or products, essentials to manage the disasters in the phases of preparedness, assessment and mitigation. In Table 4 are specified each product and their general characteristics.

\begin{tabular}{|c|c|}
\hline Products & Description and Uses \\
\hline $\begin{array}{c}\text { Level } 0 \\
\text { Data in series or } \\
\text { rows }\end{array}$ & $\begin{array}{l}\text { Synchronized data frame, compatible } \\
\text { with computerized data protocols. }\end{array}$ \\
\hline $\begin{array}{l}\text { Level } 1 \\
\text { Radiometric } \\
\text { correction } \\
\text { products }\end{array}$ & $\begin{array}{l}\text { Matrix of data radiometrically } \\
\text { corrected, without geometric correction. }\end{array}$ \\
\hline $\begin{array}{l}\text { Level } 2 \\
\text { Systematized } \\
\text { geometric } \\
\text { correction } \\
\text { products }\end{array}$ & $\begin{array}{l}\text { Radiometric and geometric correction } \\
\text { using systematic models without the use } \\
\text { of terrestrial control points (GCP). }\end{array}$ \\
\hline $\begin{array}{c}\text { Level } 3 \\
\text { Products with } \\
\text { precise geometric } \\
\text { correction } \\
\end{array}$ & $\begin{array}{l}\text { Radiometric and geometric correction } \\
\text { using terrestrial control points (GCP). }\end{array}$ \\
\hline $\begin{array}{c}\text { Level } 4 \\
\text { Correction } \\
\text { products based on } \\
\text { digital terrestrial } \\
\text { model } \\
\end{array}$ & $\begin{array}{l}\text { Radiometric and geometric correction } \\
\text { with terrestrial control points and digital } \\
\text { terrestrial model to suppress the effects } \\
\text { of displacement by land relief }\end{array}$ \\
\hline
\end{tabular}

Along the disaster management, the response time is a key issue. Therefore, the remote sensing images play an important role for the decision making at the moment to evaluate the aspects linked to the disaster. Each type of disaster has its owns characteristics in particular or physical parameters that need to be assessed in reference to special types of images generated through a quick and dynamic process that permits a rapid and timely response in emergency scenarios. As it is specified in Table 4, the row data of the images downloaded from VRSS-1 and VRSS-2 in orbit operation, need to be processed and also treated to remove from them the radiometric and geometric errors, between others errors that allows generate images processed to different levels in function to the necessities or requirements of the users. The Radiometric correction consist in removed from the images the errors caused for the variations of the sun angle and atmospheric effects, while the Geometric correction is applied to remove from the images the errors produced for the haze, the scan lines and speckles. Hence, in view of count with a fast and reliable process to management the different production of images levels with particular characteristics for each type of disasters and even supporting the decision making during the disasters management, is implemented a model to images management and processing in the VRSS-1 and VRSS-2 Ground Segment in Emergency, the Figure 8 shows an overview of the developed schema:

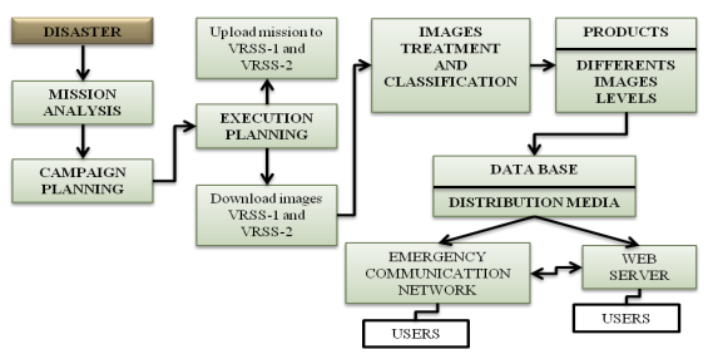

Figure 8. VRSS-1 and VRSS-2 images management and processing in emergency

\subsection{VENESAT-1 Transponders and Radiofrequency Characterization for Emergency Services in Disasters}

The communications satellite VENESAT-1, inside the emergency communication network has as main function to handles all the communications traffic and also provide the technology solutions in reference to the communications services required in the areas affected for disasters. In the same way, in combination with the remote sensing satellite VRSS-1 and VRSS-2 in the emergency network has the ability to transmit and receive different types of images in function to the technologies solutions implemented. The VENESAT-1 is designed with the communication payload described as follow: Fourteen (14) C-Band channels with $36 \mathrm{MHz}$ bandwidth and operation Uplink Frequency: $6.05 \mathrm{GHz}$ to $6.35 \mathrm{GHz}-$ Operation Downlink Frequency: $3.825 \mathrm{GHz}$ to $4.125 \mathrm{GHz}$. Twelve (12) KuBand channels with $54 \mathrm{MHz}$ bandwidth and Operation Uplink frequency: $14.08 \mathrm{GHz}$ to $14.5 \mathrm{GHz}-$ Operation Downlink frequency: $11.28 \mathrm{GHz}$ to11.7GHz. Two (02) Ka-Band channels with $120 \mathrm{MHz}$ bandwidth and Uplink frequency: $28.8 \mathrm{GH}$ to 29.1 GHz-Operation Downlink Frequency: $19.0 \mathrm{GHz}$ to $19.3 \mathrm{GHz}$, one (01) Antenna in C-Band, two (02) antennas in $\mathrm{Ku}-\mathrm{Band}$ and one (01) antenna in Ka-band. (CAST, 2007b).

Regarding the operation frequencies of the VENESAT-1 payload and the atmospheric attenuation that these frequencies can suffered when they propagate through the free space in specific due to the tropospheric attenuation is characterized the use of the VENESAT-1 radiofrequency spectrum as is specified in Table 5 with the aim to get a good performance of the communications links to be designed in case of disasters, technical aspects, such as: that the frequencies under $40 \mathrm{GHz}$, the attenuation is less than $0.02 \mathrm{~dB} / \mathrm{km}$. However, the rain attenuation for C-band, in heavy rain to $16 \mathrm{~mm} / \mathrm{h}$ is $0.03 \mathrm{~dB} / \mathrm{km}$, for the moderate rain to $4 \mathrm{~mm} / \mathrm{h}$ is nearly zero. For Ka-band $30 \mathrm{GHz}$, for moderate rain is $0.9 \mathrm{~dB} / \mathrm{km}$, for heavy rain, it can reach $2 \mathrm{~dB} / \mathrm{km}$. Likewise, the cloud and fog attenuation is very small, but for frequency high than $10 \mathrm{GHz}$, must be take in consideration. (Chai, J., 2007b)

\begin{tabular}{|c|l|l|}
\hline $\begin{array}{c}\text { Frequency } \\
\text { Band }\end{array}$ & Uses in Case of Disasters & \multicolumn{1}{|c|}{ Vulnerability } \\
\hline \multirow{3}{\text{C-band}}{} & $\begin{array}{l}\text { Earthquake, Landslide, } \\
\text { Storms, Tornado, wildfires, } \\
\text { Hurricane, Coastal } \\
\text { Tsunami, desertification } \\
\text { Erosion, work } \\
\text { and deforestation. }\end{array}$ & $\begin{array}{l}\text { This frequency work } \\
\text { properly } \\
\text { significant perturbation in } \\
\text { adverse atmospheric } \\
\text { conditions }\end{array}$ \\
\hline Ku-band & Earthquake, Landslide & $\begin{array}{l}\text { Cannot be used in adverse } \\
\text { atmospheric conditions }\end{array}$ \\
\hline Ka-band & Earthquake, Landslide & $\begin{array}{l}\text { Cannot be used in adverse } \\
\text { atmospheric conditions }\end{array}$ \\
\hline
\end{tabular}

Table 5. VENESAT-1 Spectrum characterization for disasters 
As result, it is noticed that the VENESAT-1 C-band Payload offers more reliability taking into account its less vulnerability against adverse atmospheric conditions in case of disasters.

\subsection{Technology Solutions Formulation for Disasters Management}

The VENESAT-1 platform and its Teleport integrated in the emergency communications network have the ability to support the implementation of different technologies solutions with the objective to satisfy the different communications services required in the affected area in case of disasters. The Teleport counts with dedicates satellites HUBs to provide a great verities of services, various communications infrastructure resources and connection to the national communication terrestrial network, among other capacities for communications services. Some of the services solutions available through the VENESAT-1 platform and its Teleport integrated in the emergency communications network are: video conferences satellite internet, satellite cellular phone, satellite radio broadcasting, satellite TV, telemedicine services, data bases for control and records of human or material losses, video cameras, on site operation infrastructure for disaster management, on site infrastructure for satellite images download and processing, computer network cloud, VSAT network and UAV control center for land surveillance and assessment. A General overview of a cellular backhaul implementation in case of emergency is shown in Figure 9.

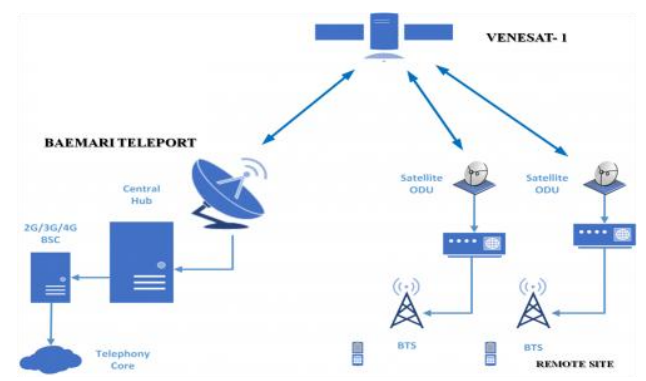

Figure 9. Technology solutions for disasters management Cellular Satellite Backhaul

Likewise, considering the Figure 9, which discribes a Cellular Backhaul architecture in star topology, is carried out using the software SATMASTER (tool for communications links design) the link budget calculation for the Single Channel per Carrier service correspondent to the implantation of a Cellular Backhaul, using the VENESAT-1 transponders and its teleport in case of disasters that demand this type of services. Table 6 and Table 7 present the results obtained for the uplink and downlink of the aforementioned service.

\begin{tabular}{|l|l|}
\hline \multicolumn{2}{|c|}{$\begin{array}{c}\text { Cellular Backhaul SCPC Radio Base Station Baemari Site -Rosalia Site } \\
\text { (Forward Link) }\end{array}$} \\
\hline \multicolumn{2}{|c|}{ Uplink and Downlink Parameters } \\
\hline Transponder: Ku-1A & TX EIRP: 63.53 dBW \\
\hline Carrier Type: Digital & $\begin{array}{l}\text { HPA Power Required: } 2.8556 \\
\text { dBW }\end{array}$ \\
\hline Antenna TX Gain: $64.15 \mathrm{dBi}$ & Carrier Modulation: 4-PSK \\
\hline Antenna RX Gain: 62.90 dBi & Carrier Bandwidth: $1.9575 \mathrm{MHz}$ \\
\hline Uplink Frequency: $14158.14 \mathrm{MHz}$ & $\begin{array}{l}\text { Transponder Carrier Occupied } \\
\text { BW: 0.4445 MHz }\end{array}$ \\
\hline Downlink Frequency: $1358.14 \mathrm{MHz}$ & SFD: -98.598 dBW/m ${ }^{2}$ \\
\hline Carrier Polarization: H/V & $\begin{array}{l}\text { Carrier Downlink EIRP: } 33.18 \\
\text { dBW }\end{array}$ \\
\hline
\end{tabular}

\begin{tabular}{|l|l|}
\hline \multicolumn{2}{|c|}{$\begin{array}{c}\text { Cellular Backhaul SCPC Radio Base Station Rosalia Site - } \\
\text { Baemari Site (Return Link) }\end{array}$} \\
\hline \multicolumn{2}{|c|}{ Uplink and Downlink Parameters } \\
\hline Transponder: Ku-1A & TX EIRP: 52.91 dBW \\
\hline Carrier Type: Digital & $\begin{array}{l}\text { HPA Power Required: 7.78 } \\
\text { dBW }\end{array}$ \\
\hline Antenna TX Gain: 46.5 dBi & Carrier Modulation: 4-PSK \\
\hline Antenna RX Gain: 45 dBi & $\begin{array}{l}\text { Carrier Bandwidth: 1.9575 } \\
\text { MHz }\end{array}$ \\
\hline Uplink Frequency: 14160.10MHz & $\begin{array}{l}\text { Transponder Carrier } \\
\text { Occupied BW: 0.4445 MHz }\end{array}$ \\
\hline $\begin{array}{l}\text { Downlink Frequency: } 11360.10 \\
\text { MHz }\end{array}$ & SFD: -109.208 dBW/m² \\
\hline Carrier Polarization: H/V & $\begin{array}{l}\text { Carrier Downlink EIRP: } \\
16.53 \mathrm{dBW}\end{array}$ \\
\hline
\end{tabular}

Table 7. Cellular Backhaul SCPC link budget (return link)

\subsection{Emergency Communications Network Architecture for Disaster Management in Venezuela}

The main task of the Emergency Communication Network for Disasters Management is to serve as support of the conventional communications Networks in case of disasters that affected these infrastructures in Venezuela. In this sense, the network operates in function of three satellite platforms. The communications satellite VENESAT-1 and the remote sensing satellites VRSS-1 and VRSS-2. The VENESAT-1 has the main function in the network of handle all the communications traffic and also provide the capability to implement the communications technology solutions required in the areas affected for the disasters; in combination with The VRSS-1 and VRSS-2 has the aim to receive images from the ground station of both satellites to then transmitted them through the technologies solutions implemented in case of disasters to specifics areas. The main task of the VRSS-1 and VRSS-2 are take images over the affected areas according with the different missions loaded from the ground station; following also the operational strategies designed to management both platform in emergency for quick and reliable response in disasters. In Figure 9 is shown the architecture designed to the Venezuelan Emergency Communication Network for Disaster Management.

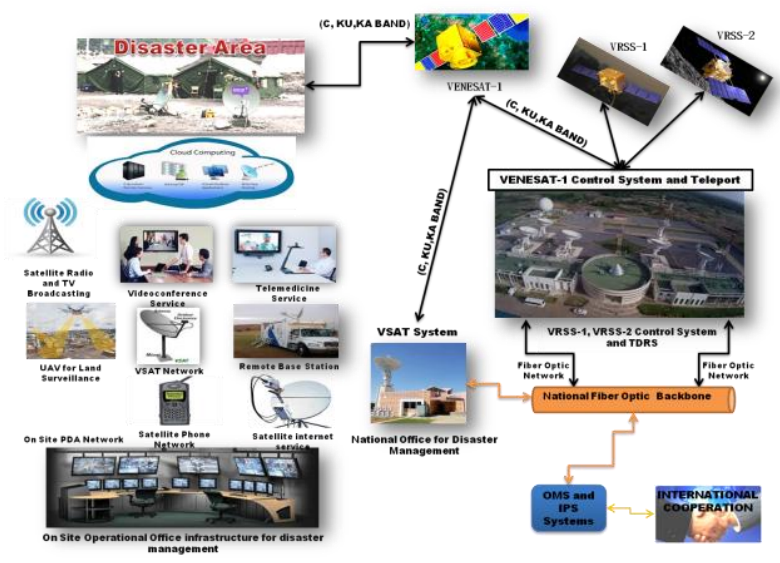

\section{CONCLUSIONS}

The development of new technologies for disaster Managament is an essential task that is studied for many countries and organization around the world. Therefore, look for new tools or 
medias appropriate to carry out the preparation, mitigation or recovering from the effects of the phenomena associated to the disasters is a big challenger for the different actors involve in this matter. Regarding this point of view, Venezuela at the present time counts with the satellites resources in orbit operation that provide the capability to increase in the country the capacities to Managament disasters events. In this sense, the designed and implementation of the Emergency Communications Network for Disasters Management in Venezuela presented in this paper which combine the use and integration of the communication satellite VENESAT-1 and the remotes sensing satellites VRSS-1 and VRSS-2 and their ground stations, is a novel communications and remote sensing applications platform essential and suitable to help in the Prevention, Mitigation, Preparedness, Response and Recovery of the national communications systems in case of disasters occurrences. The Network infrastructure give the facilities to put in operation different communications technologies solutions and a variety of options or schemes to the images exchange between the actors involved in the disaster management tasks or the population in general affected for disasters directly. In the same way, the Network makes available useful data for emergency response and infrastructures recovery in the event of disasters which affect the public and private communications infrastructures. On the other hand, the network can adopt a global character and it may be used to support others Latin American Countries in case of disasters or damages that affect the Communications Network infrastructures of these countries, since the VENESAT-1 footprint cover the region and the remote sensing satellites VRSS-1 and VRSS-2 has a global coverage.

\section{REFERENCES}

ABAE, 2010. VRSS-1 performance specifications. Caracas, Venezuela.

ABAE, 2016. VRSS-2 performance specifications. Caracas, Venezuela.

Canada center for Remote Sensing, 2006b. Fundamentals of Remote Sensing. Natural Resources naturelles. Canada. pp.39

Chai, J., 2007b. System Design of Satellite GCS Satellite GCS radiofrequency atmospheric attenuation BITTT. Beijing, China. pp. 25.

CAST, 2007b. VENESAT-1 Transponder Subsystem Design. Beijing, China. pp. 16-87.

ESCAP, 2013a. Technology and Disaster Risk Reduction Division Sound practices in space technology applications for disaster risk reduction and inclusive and sustainable development. Bangkok, Thailand. pp. 3.

NASA, 2015b. Climate variability, hydrology, and flooding, fundamentals of remote sensing. GEO-Latin American \& Caribbean water cycle capacity building workshop. Cartagena, Colombia.

Gibson, J., 2000. Introductory Remote Sensing, Principles and Concepts. Routledge, London.

Hodgson, M., Bandana K., 2008a. Modeling the potential swath coverage of nadir and off-nadir pointable remote sensing satellite-sensor systems. Department of geography, University of South Carolina, Columbia, USA. Vol. 35, No. 3, pp. 147154.

ITU, 2003a. Telecommunications the role of information and communication technologies in disaster response, mitigation and prevention SAVE LIVES. Geneva, Switzerland. pp. 3.

Mehdi, A., 2012b. The role of the mobile satellite services and remote sensing satellite in disaster management. Department of electrical engineering, University of technology, Tehran, Iran. pp. 4010-4013.

Ministry of Mines and Hydrocarbons, 1970b. Stratigraphic Lexicon of Venezuela. Caracas, Venezuela.

Nagesh, K., 2000b. Remote Sensing Systems, Spatial and spectral resolutions, IISc, Bangalore.pp.2-3.

Rabolli, A., Gulich, M., 2005. National commission of spatial activities "Basic knowledge about remote sensing satellites NOAA". $2^{\text {nd }}$ edition. Pp. 32

Rondon, J., 2015b. Geological faults of Venezuela, University Institute Santiago Mariño. Valencia, Venezuela. pp 3-7

World risk Report, 2016. United Nations University Institute for Environment and Human Security UNU-EHS. pp 74. 